\title{
Fenomenologia e hermenêutica. De Husserl a Ricoeur Sentido de um conflito
}

\section{Paula Ponce de Leão}

"Il est plus facile que l'on croit de se hair. La grâce serait de s'oublier. Mais si tout orgueil était mort en nous, la grâce des grâces serait de s'aimer humblement

soi-même comme n'importe (...)" [quelqu'un d'autre.] G. Bernanos, Journal d'un curé de campagne, Paris, Plon, 1936, 363.

A reflexão que apresento não pretende revestir um caracter histórico, nem tão pouco procura estabelecer uma comparação de caracter meramente formal entre fenomenologia e hermenêutica. Se pensar é, antes de mais, pensar com outros, é também e sobretudo pensar depois deles. No tempo de crise que é o nosso, as imagens tradicionais e a cristalização dos conceitos esperam novas simbolizações' capazes de se contraporem às noções de estrutura e de funçño que no presente as ideologias mais diversas e os sistemas mais "especializados" não só sancionam como requerem. Face à crise a filosofia torna-se crítica e ao sê-lo tem consciência da impossibilidade de atingir verdades irrefutáveis. Dialogar com Husserl e Ricoeur torna-se, por isso mesmo, tarefa inadiável quando se procura descobrir o sentido do existir humano.

Fenomenologia e hermenêutica: a consciência no mundo

Husserl é interlocutor fundamental, porque companheiro imprescindível no caminho onde o rigor da razão ${ }^{2}$ tem de partir do mundo para a busca incessante do fundamento, do sentido do fundamento ${ }^{3}$. Também Ricoeur ao pensar o homem como tarefa ${ }^{4}$, aventura existêncial e social em si mesmo irredutível, tal como ao considerar a hermenêutica do si como condição da unidade temática do agir humano, se propõe responder à reflexão actual sobre os limites da consciência. A pertença mútua entre fenomenologia e hermenêutica é posta desde logo em evidência, não só pela inerência da consciência ao mundo, como pela recusa da instrumentalização do homem, como ainda pela presença não temática, quer ao nível do individual quer do colectivo, da questão do incondicionado. Estes items constituem o solo, que

1 G. HOTTOIS, Essais de philosophie bioéthique et biopolotique, Paris, Vrin, 1999, 15-18.

2 E. HUSSERL, Logische Untersuchungen - I, II, Haia, M. Nijhoff, 1955; trad. franc. R. Elie, Recherches logiques, Paris, PUF, 1959. Doravante citado pela sigla $L U$.

3 E. HUSSERL, $L U, 72$.

4 P. RICOEUR, Soi-même comme un autre, Paris, Seuil, 1990. Doravante citada pela sigla SA. 
sendo comum tanto a Husserl como a Ricoeur, pressupõe um movimento de contínua ultrapassagem que só o dinamismo intencional da consciência desencadeia e permite. A síntese entre o incondicionado e o individual ou entre o princípio universal e o acontecimento concreto é, porém, resolvida de forma distinta por ambos. Husserl, graças à teoria da intencionalidade e à prática das reduções, move-se no campo da consciência representativa justificando a possibilidade da adequação entre estes dois níveis de realidade de forma idealista ${ }^{5}$. Ricoeur por sua vez aponta, como condição da relação entre realidades diferentes, introduz a consciência hermenêutica mediação que pela dialéctica religa o acto de pensar, com o acto de ser.

Porque na sua reflexão sublinham diferentes ordens de causalidade ${ }^{6}$, Husserl tinha ignorado, ao contrário de Hegel, a experiência do trágico como portadora de sentido, enquanto que Ricoeur considerando a experiência da falta e da culpa face ao outro e ao mundo o reintroduz enquanto lugar do ainda por pensar. O trágico não pode, por isso mesmo, ser reduzido em Ricoeur à dimensão negativa do limite ou da finitude ${ }^{7}$. A positividade que o habita, desde logo espreita no mais íntimo do seu núcleo conceptual já que, embora fique despojado do carácter absoluto da autonomia, o homem não fica nele esvaziado de conteúdo, nem reduzido à inércia dum objecto. Pelo contrário, enquanto livre e capaz, as escolhas que seguidamente faz expressam, não só a sua criatividade como a sua responsabilidade, ao revelarem-no participante num jogo onde a compreensão da identidade pressupõe a experiência da diferença entre o homem, o outro e o mundo. Fink ${ }^{8}$, intérprete muito próximo de Husserl, tinha recorrido à noção de jogo para mostrar a forma privilegiada do homem se relacionar com a totalidade do mundo. Pela actividade lúdica o homem participa efectivamente na infinitude do mundo ao qual pertence ${ }^{9}$. Na sua perspectiva, o caracter lúdico da reflexão permite que representação e imagem se interliguem. Ricoeur, enquanto hermeneuta não parte, ao contrário de Gadamer, da noção de jogo para repensar a relação compreensiva entre fenomenologia e ontologia, entre pensar e ser. Será através das noções de corpo próprio, de alteridade e de consciência que se propõe antes pensar a sua articulação $0^{10}$.

A dimensão idealista que desde logo parece impender sobre a fenomenologia, é por Ricoeur atribuída ao próprio Husserl ${ }^{11}$. Porque se lhe impõe ultrapassá-la Ricoeur começa por recorrer à análise do voluntário e do involuntário, a que se irá seguir o recurso à hermenêutica do texto e por fim à hermenêutica do si. Todavia, ao apresentar um caracter analítico-reflexivo, o si-mesmo situa-se na história, implicando consequentemente a fragmentação das questões que ao longo do tempo são continuamente suscitadas. Esta forma de abordar o agir humano suscita porém algumas questões. Se Husserl, no desejo de salvaguardar a universalidade do conhecimento, reduzia a identidade de cada um à subjectividade transcendental e dava à fenomenalidade da consciência pura um caracter mais originário do que o da própria realidade percepcionada, a acção humana ao ser considerada por Ricoeur a partir das "potencialidades" do si não porá de igual modo em causa a unidade do sujeito que lhe subjaz? Por outro lado, se a polissemia da alteridade justifica no pensar ricoeuriano, a diversidade do sentido, como entender o fundamento do

5 P. RICOEUR, À l'école de la phénoménologie, Paris, Vrin, 1986, 18.

6 Enquanto Husserl sublinha a causalidade eficiente, Ricoeur preocupa-se com a causalidade formal.

7 P. RICOEUR, Le mal, Geneve, Labor et fides, 1986, 38-44.

8 E. FINK, Spiel als Weltsymbol, Stutegart, 1966, 240.

9 E. FINK, op. cit., 127.

10 P. RICOEUR, SA, 367.

1 P. RICOEUR, Du texte à l'action. Essai d'herméneutique II, Paris Seuil,1986, 39. Doravante $T A$. 
próprio acto de pensar enquanto garante da dialéctica entre o mesmo e o outro? Como pode o outro estar presente na forma do si-mesmo encontrar o sentido sem pôr em causa a sua singularidade? Como entender a solicitude? Mais ainda, como justificar a unidade da atestação se o testemunho que no mais íntimo a constitui parece revelar um caracter ambivalente ${ }^{12}$ ?

Por diferentes caminhos, a hermenêutica de Ricoeur e a fenomenologia de Husserl reencontram-se numa proposta comum, a partir da qual a interpretação do homem terá hoje de refazer-se, a noção de carne. Brevemente procurarei reconstruir o longo debate que foi necessário a Ricoeur encetar para continuar a pensar, sem esquecer Husserl, mas diferentemente dele. "Por um lado, (diz Ricoeur), (...) a fenomenologia é um pressuposto inultrapassável da hermenêutica. Por outro lado porém, a fenomenologia requer um pressuposto hermenêutico"13.

\section{Pertença e conflito}

Ao traduzir as Ideen, Ricoeur ${ }^{14}$ situa Husserl na continuidade do esforço que caracteriza a filosofia ocidenta $l^{15}$ onde a reflexão sobre o homem tinha com ponto mais alto a análise do acto de conhecer ficando remetidos para segundo lugar,porque situados no plano prático, a natureza do fazer e do agir. Ao retomar a esfera do conhecimento como dimensão própria e peculiar do homem, Husserl interliga-a com a noção de mundo, horizonte imediato que desde logo importa explicar. E dentro desta óptica que Husserl se aproxima de Kant ao sublinhar não só a importância do método na reflexão humana, como também ao procurar o fio lógico-ontológico que garante a relação entre o sujeito transcendental e o fenómeno considerado como "leitura" da realidade. Hume e a filosofia analítica ajudam, por sua vez Husserl a compreender que a verdade tem de ser pensada a partir da experiência concreta entendida não só como base das significações e das coisas, como também dos valores e das pessoas. Só neste sentido, a ida "às coisas mesmas", "Zu den Sachen selbst"'16, que Husserl proclama, se torna condição do método descritivo e da análise intencional. É, porém, a temática do Cogito e da dúvida desenvolvida por Descartes que constitui o centro ontológico da proposta husserliana. Se a dúvida permitia a Descartes afastar as falsas evidências, também a redução fenomenológica as procura eliminar. Mais ainda, em Husserl o cogito ganha uma dimensão totalmente nova, já que não surge como verdade primeira, mas como condição da própria verdade. Neste sentido, a fundamentação da filosofia ao depender da auto-compreensão fenomenológica exige que a consciência de si seja pensada através de um método onde a subjectividade transcendental para ser atingida tenha de recorrer.à teoria da redução. Porém, tal como Ricoeur desde logo sublinha, a redução modifica a própria noção de consciência ${ }^{17}$, que Husserl inicialmente tinha partido. O caracter pessoal da consciência que presidia à apreensão do fenómeno sofre uma transformação ao tornar-se instrumento do conhecimento universal dos sendos. Se a fundamentação

12 J. GREISCH, "Témoignage et attestation", in J. Greisch (dir), Paul Ricoeur: L'herméneutique à l'école de la phénoménologie Paris, Beauchesne, 1995, 307.

13 P. RICOEUR, TA, 40.

14 E. HUSSERL, Ideen zu einer reinen Phaenomenologische und phaenomenologischen Philosophie, Jahrbuch für Philosophie und phünomenologisch Forschung, t. I, Halle, M. Niiemeyer, 1913; trad. franc. P. Ricoeur, Idées directrices pour une phénoménologie, Paris, Gallimard, 1950, 1985. 
fenomenológica exige uma analítica intencional da consciência, como garantia do movimento que vai da presentação à representação, então esta atitude revela simultaneamente como é através da enunciação dos limites do acto de conhecer pessoal, que a auto-doação ou saber originário pode ser pensado como raiz do próprio acto de conhecer ${ }^{18}$. Como responder, porém, às questões que o logos transcendental levanta ao constituir o princípio onde se alicerça a teoria da intencionalidade? Como entender que aspectos tão diversos como a ida "às coisas mesmas" e a confusão no "fenómeno"entre o pensável e o real possam simultaneamente estar alicerçados num mesmo princípio sem ser a partir de qualquer "engano" intelectual ? Não se debaterá neste campo Husserl com a velha aporia do intelecto agente que tão pesada de consequências foi para Aristótele ${ }^{19}$ ? A reflexão ricoeuriana não é, em si mesma, senão a tentativa de responder a esta questão deixada ainda em aberto pela fenomenologia. A abrangência do método descritivo assim como a análise intencional da consciência que rompia com a identificação cartesiana entre consciência e consciência de si aparece a Ricoeur como a inovação fundamental da fenomenologia. Ao permitir porém a reposição do idealismo transcendental, a intencionalidade fenomenológica contrapunha-se ao projecto, cedo começado a desenvolver por Ricoeur, onde o método da "reflexão segunda" aurido de Gabriel Marcel e as orientações para o concreto, características da filosofia reflexiva, embora sujeitos a tensões, se conjugavam ${ }^{20}$. Separar o idealismo transcendental do método descritivo requerido pela intencionalidade e tentar afastar o primeiro recorrendo para tal a vários momentos temáticos, constituiu a primeira preocupação que Ricoeur se deu a si próprio. $\mathrm{O}$ alargamento do campo de aplicação da análise intencional à esfera da vontade, à hermenêutica dos textos, que implicava o despojamento do eu, e finalmente o recurso à hermenêutica do si, não são senão a forma de Ricoeur propôr um novo modelo de reapropriação de eu, que afastando-se do psicologismo recusasse, por igual, a universalidade da subjectividade transcendental.

\section{O percurso da diferença}

O pensamento ricoeuriano perseguiu, desde sempre, uma concepção alargada de consciência que ao descobrir-se necessariamente ligada à existência, se reconheceu como incarnada. O itinerário filosófico de Ricoeur inicia-se com a tradução das Ideen I, onde na introdução a ambivalência da fenomenologia desde logo é referida. Para Husserl a análise intencional, se por um lado confirmava o primado da representação sobre os conteúdos afectivos e volitivos, por outro lado afirmava a impossibilidade de pensar sem ser a partir da experiência concreta. A ambiguidade que presidia à redução fenomenológica tornava-se assim passível de duas interpretações que procuravam esclarecer a fenomenalidade do fenómeno ${ }^{21}$.

Para Max Scheller a redução permitia o aparecer à consciência de qualquer fenómeno, para Fink, pelo contrário, a redução era quase a produção da fenomenalidade do fenómeno que, em certo sentido, era mais real do que o próprio fenómeno. Ricoeur procura realizar uma interpretação que se oponha tanto ao realismo como idealismo e que, sendo neutra, permita resistir à maneira de Merleau-Ponty, a qualquer descrição com caracter definitivo. A interpretação amplificante que em Philosophie de la volonté começa por propôr, alarga a compreensão do

18 E. HUSSSERL, Ideen I, parag. 24.

19 ARISTÓTELES, De anima, , 1 I, c 5.

20 P. RICOEUR, Réflexion faite, Paris, Esprit 1995, 17. Doravante citada pela sigla RF.

21 P. RICOEUR, $R F, 19$. 
homem ao incluir nela a análise dos actos involuntários que Gabriel Marcel tinha considerado deverem ser analisados por uma reflexão segunda e que para K. Jaspers se integravam em situações limite.

Se a consciência é uma consciência de ... e se a realidade se reduz a ser apenas uma realidade na consciência que percebe, i. e., se a relação entre o noético e o noemático só acontece perfeitamente ao nível da "representação" (Vorstellung) será legítimo pensar que o mesmo aconteça ao nível prático da consciência? Segundo Husserl a extensão da análise intencional aos vividos "sintéticos" de que fazem parte os afectos e a volição não põe em causa os actos "objectivantes" da consciência, importa apenas distinguir os vividos "simples" dos vividos de ordem "complexa" que se fundam nos primeiros ${ }^{22}$.

Em Volontaire et involontaire $I^{23}$ Ricoeur compraz-se em mostrar a fecundidade da análise descritiva aplicada às funções práticas da consciência. A intencionalidade ao aplicar-se à vontade revela, porém, uma consequência que Husserl parecia não ter previsto. Se a preocupação deste autor consistia em querer provar o primado da representação sobre as dimensões práticas dos afectos e da volição, Ricoeur vai exactamente mostrar como, ao aplicar-se à dimensão prática da consciência, a redução não só é fecunda como não se subordina de forma alguma à representação. Pelo contrário, a dimensão transcendental que caracteriza a especulação não esgota a consciência que só tem sentido porque incarnada ${ }^{24}$, ao fundar-se, portanto, num projecto alargado da existência no mundo. Na Krisis ${ }^{25}$ Husserl irá chamar Lebenswelt a este projecto ao qual Ricoeur chamará "consciência no mundo" 26 . A passagem da fenomenologia transcendental à fenomenologia ontológica não se funda no nível representativo, que em si está enraízado num fundamento mais originário ${ }^{27}$. Não é apenas a consciência intelectual que dá sentido ao mundo, a consciência prática pela vontade abre aos possíveis práticos onde, paciência e revolta, passividade e iniciativa também se manifestam e, embora dependendo de um fundamento que não escolheram, dão igualmente sentido ao mundo. É neste espaço do involuntário que para Ricoeur a culpabilidade se inscreve enquanto zona de indeterminação da vontade. A passividade da consciência é a marca do seu enraízamento num fundamento que a transcende. Será então pela negativa que a experiência ontológica se verifica. A culpabilidade não é redutível, por isso mesmo, a uma leitura meramente legalista. Falha primitiva, a culpa requer em contrapartida uma exegese do $\mathrm{mal}^{28}$. A passagem do eidético ao ontológico corresponde ao despojamento do eu que se reconhece culpado, o que vem tornar impossível a realização de uma "poética da vontade" tal como Ricoeur havia prometido. A vontade serva, porque passiva face a uma receptividade essencial, revela-se igualmente aberta ao que de fora se lhe impõe. Tal deficiência impede-a, embora querendo, de construir a relação ao ser. A questão do fundamento tem então de encontrar novas vias onde possa constituir objecto de reflexão. A interpretação da linguagem vem, segundo Ricoeur, substituí-la através da procura do sentido já que os símbolos e os mitos são as formas primeiras do fundamento se revelar de forma indirecta a que só posteriormente a razão irá ter acesso. Explicar o que é a

22 E. HUSSERL, Ideen I, parag. 116.

23 P. RICOEUR, Volontaire et involontaire, Paris, Aubier-Montaigne, 1950. Doravante citada VI.

24 P. RICOEUR, EP, 55.

25 E. HUSSERL, Die Krisis der europaeischen Wissenschaften und die transzendentale Phaenomenologie, Haia, M. Nijhoff, 1954.

26 P. RICOEUR, EP., 119.

27 B. STEVENS, "L'évolution de la pensée de Ricoeur au fil de son explication avec Husserl", Études Phénoménologiques, $n{ }^{\circ}$ II, 1990, 14.

28 P RICOEUR, VI, II, 171. 
linguagem implica, desde logo, pensar o seu poder significante. Em Le Conflit des interprétations $^{29}$, Métaphore vive ${ }^{30}$ e na trilogia de Temps et récit ${ }^{31}$ a que se vem juntar Du texte à l'action ${ }^{32}$ Ricoeur analisa com o maior rigor a questão base que a linguagem levanta e que, paradoxalmente, a Torre de Babel já enunciava. A linguagem vulgar é expressão de um modelo ideal, ou resulta do uso que os homens dela fazem no quotidiano? A solução desta dicotomia não apresenta solução em Wittgenstein nem nos analistas da linguagem, nem tão pouco no estruturalismo. Ricoeur depois de ter dialogado com a semântica e a semiótica procura encontrar um encadeamento que permita estabelecer uma relação de continuidade entre elas e não uma relação de simples oposição ${ }^{33}$. A teoria da significação proposta pela fenomenologia surge-lhe como capaz de estabelecer a mediação entre semântica e semiótica. A descrição lógica ao depender da fenomenologia do vivido transforma, para Ricoeur, a linguagem na melhor forma de estabelecer a mediação entre a universalidade dos conceitos e a experiência pré-linguística da consciência. A redução desempenha, na mediação, um papel fundamental porque para encontrar a génese do sentido impõe-se ultrapassar a atitude natural. O signo, que em si mesmo é vazio, só tem sentido enquanto se substitui à coisa visada, cuja percepção se transforma numa modalidade fundamental porque decide se este se adequa ou não à realidade visada. E, para Ricoeur, na fenomenologia "A linguagem deixa de ser uma actividade, uma função, uma operação entre outras: ela identifica-se ao meio significante, à trama dos signos atirados como uma rede sobre o nosso campo de percepção, de acção, de vida" ${ }^{34}$. Porque não basta distinguir um signo de todos os outros, mas importa passar do campo semiótico das diferenças para o campo semântico das relações Metaphore vive e Temps et récit conjugando a palavra, a frase e a narração "criam uma ordem progressiva de estruturas e de processos onde a configuração de um texto vai a seguir ser completada pela refiguração do leitor. Desta forma, Ricoeur compreende a teoria da significação husserliana e mantém o caracter transcendental que lhe é peculiar para poder ligar a instância do discurso à realidade concreta e à sua retro-referência. A univocidade das significações requer, porém, uma Auslegung ${ }^{35}$ que permita não só encontrar o sentido unívoco das expressões mas que possibilite também pôr em relevo o sentido do mundo objectivo.

A remissão entre fenomenologia e hermenêutica, que como vimos Ricoeur sublinhou, assenta num círculo fundamental. A fenomenologia tem de admitir que o seu método requer sempre numa interpretação. Para ser possível encontrar uma significação unívoca ${ }^{36}$ torna-se necessário interpretar as presentificações. A explicação é, de certo modo, uma interpretação porque procura encontrar um sentido que já lá está, por isso mesmo visa a compreensão. A egologia husserliana quando atinge seu apogeu nas Cartesianische Meditationem und Pariser Vortraege $e^{37}$ perde a possibilidade de pensar o outro como diferente de si. A alteridade do outro tende a ser a de um outro eu mas porque a constituição precede o ego monádico, a intersubjectividade nela radica. O horizonte de sentido

P. RICOEUR, Le Conflit des interpretations. Essais d'herméneutique, Paris, Seuil, 1969.

30 P. RICOEUR, Métaphore vive, Paris, Seuil, 1975.

31 P. RICOEUR, Temps et récit, I, II, III, Paris, Seuil, 1983, 1984, 1985.

32 P. RICOEUR, Du texteà l'action. Essais d'herméneutique II, Paris Seuil, 1986.

33 P. RICOEUR, Le Conflit des interpretations. Essais d'herméneutique, op. cit., 246-7. Doravante CI.

34 P. RICOEUR, $\mathrm{Cl}, 243$.

35 P. RICOEUR, TA, 61 .

36 P. RICOEUR, TA, 63.

37 E. HUSSERL, Cartesianische Meditationm und Pariser Vortaege Haia, M. Nijhoff, 1950. 
que precede a interpretação é infinitamente aberto e inesgotável. São neste sentido os limites apresentados pela fenomenologia que paradoxalmente põem a descoberto a sua dimensão hermenêutica.

A concluir...

O recurso ao trans-subjectivo que a intencionalidade husserliana representa, se admite a realidade velada, redu-la a "uma realidade segunda", já que o pensar, ao substituir-se ao ser, aprisiona-o numa idolosfera de caracter essencialista. A passividade humana, ao constituir-se como um olhar, movimenta-se entre o ver e o pensar que o compreender espacialmente estrutura. Cabe ao homem, na perspectiva fenomenológica, apenas o poder de ler e de refletir sobre as aparências que se lhe oferecem. Reconhecendo a ida ao mundo e a descrição dos fenómenos como momentos fundamentais da fenomenologia, a Ricoeur importa também pensar a dimensão concreta do homem simultaneamente corpo, acção, linguagem e relação. Ao reconhecer, tal como Husserl, a impossibilidade de dizer o fundamento Ricoeur não o substitui, no entanto, pelo absoluto nem transforma a subjectividade num ego de caracter transcendental. Continuador da fenomenologia francesa importa-lhe, tal como a Merleau-Ponty, aproximar-se do invisível e, tal como a Levinas, reflectir sobre a alteridade do outro. Para tal impõe-se-lhe meditar sobre a consciência, simultaneamente lugar onde a dialética entre mesmidade e ipseidade desde logo acontece, para num segundo momento ser a dialéctica entre ipseidade e alteridade a tomar a primazia. Segundo Ricoeur, a alteridade faz parte do núcleo mais intimo da ipseidade. Tal pertença justifica-se fenomenologicamente pela variedade das experiências de passividade que coexistem no homem impedindo-o de ocupar o lugar do fundamento. É a carne enquanto mediadora entre a interioridade e o mundo, enquanto passividade face ao outro, que sobre ela detém poder porque diferente que, segundo Ricoeur, desde logo permite a relação de intersubjectividade. O corpo próprio pertence ao reino das coisas e do em-si. É através dele que o em-si, pelas acções intervém no mundo. A identidade pessoal exige assim, que critérios corporais e psíquicos se liguem de forma a que a identidade pessoal não seja senão a consciência que se descobre ancorada num corpo. A fenomenologia de Husserl detém um papel importante na constituição da ontologia da carne. Ao distinguir nas Cartesianische Meditationem a noção de carne da noção de corpo Husserl constrói a base para uma ontologia da alteridade. A minha carne não se pode confundir com o meu corpo senão numa dimensão muito geral em que o meu corpo se distingue do corpo dos outros. Pela noção de carne enquanto condição da constituição da minha própria identidade e antes da constituição do alter-ego e da intersubjectividade está cometida a cada um a possibilidade de se possuir e também de se conhecer. 


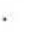

